and a peculiarly wet and thick snowstorm that occurred during the night of the thirteenth is thought to have overwhelmed the birds when in flight high overhead, soaking their plumage and dazing them. At any rate, great numbers hit the ground with fatal violence. In the morning dead and injured birds were to be seen over a wide stretch of country; on the frozen surfaces of two lakes 750,000 dead longspurs were counted, by the method of laying off sample units of area and checking the birds to be seen on these units. But in spite of this spectacular destruction of individuals the Lapland longspur was not reported the following years in the winter range of the species (Kansas, ete.) as obviously less numerous than usual. Did not the ability of the species to recover from this extraordinary calamity rest in the "factor of safety"?

There is good reason to believe that release of intra-specific pressure on the breeding grounds of a species is accompanied b:y reater productivity on the part of the remaining population. The survival chances for the young are greater where the safest type of nesting places is available to all the adults seeking to breed, and where congestion of population, and consequent drain on available food supply, has been reliever. Also, towards the end of the year, when the annual pinch of food scarcity comes into play, in the winter range, a larger proportion of maturing individuals than usual will survive. In other words, from one point of view, calamitous reduction of population benefits the immediately oncoming generations.

Let me center attention now upon the significant fact that certain of our birds are, and always have been, totally unprotected by either law or sentiment-jays, crows, linnets, shrikes and blackbirds. The rate of annual increase in those species is no different, in so far as I am aware, than it is in the vireos, warblers, mockingbirds, tanagers, and purple finches, which latter are looked upon as desirable songbirds. Yet the former are holding their own just as well as the latter, protected, species. Their numbers are always kept up to topnotch commensurately with the prevalence of their niches. They have reached the maximum population possible to them, consistent with the nature of the country, and they hold to it.

We all know of the enmity of orchardists, and agriculturists, and sportsmen toward linnets, blackbirds and blue jays, respectively. Now and then, and there is a case on record as far back as thirty years ago, "blue jay hunts" are held; in one lately recorded instance, at Hollister, San Benito County, 1,531 California jays were killed in one day, in a prize competition for the destruction of socalled "vermin." Incidentally, you will note that sportsmen feel particular animosity toward any competitor or rival in their own field! They are right after anything that can be called "vermin" from their standpoint. As lar as we can see, as a result of such campaigns-shooting of blue jays, netting of blackbirds, and poisoning of linnets-there has been only a rery temporary and local reduction in the numbers of these birds; two or three seasons bring them back to normal: that is, to the maximum numbers which the amplitude of their respective niches will warrant.

Bird population, in kind and quantity; is controlled primarily by conditions of habitat. It is a matter of food and shelter. The natural history collector, as a lactor against birds, is only an exceedingly minor influence, one which like all the others, is allowed for by the "factor of safety." My readers will begin to suspect that I have become sensitive because of the inveighing that certain well-meaning but uninformed people have undertaken against the killing of birds for specimens. I admit the scole.

JOSEPH GRINNELL

Musuum of Vertebrate Zoology, University of California

\section{ARE PERMANENT DISTURBANCES OF EQUILIBRATION INHERITED?}

THE writer of this note has just brought to completion a long series of studies upon the mechanics of equilibration in the white rat. During the course of these studies certain facts appeared which, though incidental to the original problem, may be of importance in the 
field of genetics. The facts were observed under the following conditions. As a part of our method, we found it necessary to rotate white rats day and night in small revolving cages over a period of several months. The cylindrical cages, less than a foot in diameter, were rotated in a horizontal plane, some at sixty and others at ninety times a minute. Several months after this series of continuous rotations began, a part of the subjects were removed from the rotating cylinder (a) in order to make abservations on their behavior subsequent to their long continued rotation, and (b) in order to make room for litters which were born from time to time within the cylinders. Several weeks (the time has varied from individual to individual) after these first subjects had been removed from the rotating cylinders, it was discovered that permanent changes in bodily movement and posture had taken place. The most striking changes were (a) circular movements about the nest, usually in the direction of the long continued rotation, and (b) a decided turning or twisting of the head to the right or to the left. It was discovered, moreover, that these changes in posture were occasionally accompanied by swellings and discharges from the region of the ear, and more frequently, by decreasing bodily tonicity and finally by death. Further search revealed the fact that this state of "disequilibration" was accompanied by important changes in the character and in the duration of the ocular: movements following short rotation periods ( 20 turns in 10 seconds).

Before the appearance of this state of "disequilibration," a few of the subjects with a long history of rotation were mated with other rotated and unrotated individuals solely for the purpose of adding to our experimental stock. Curiously enough, however, individuals began to appear in successive generations presenting the same types of disequilibration observed in the parents. That is to say, rotated individuals mated weeks after having been taken from the revolving nests gave offspring a part of which were disequilibrated in the same manner as their parents. Subjects of this kind have continued to appear at various intervals during the past two years. They have even been discovered in the third generation after rotation. Up to this time about sixty disequilibrated individuals have been counted in a total population of approximately five hundred.

Unfortunately, the demands of the experiments upon equilibration made it impossible to investigate adequately the genetic implications involved in these materials. Nevertheless, the facts as such were considered striking enough to warrant their presentation at a meeting of the Society of American Naturalists in 1921. The questions and suggestions received at that time have led to the conclusion that the biological aspects of the problem should be established and that definite attempts should be made to discover (a) whether the stock in our laboratory may not have given one or more mutations or segregates which, in turn, became the progenitors of the curious individuals still apparent; (b) whether an experimental method of modifying the function of an important organ has been accidentally discovered; and (c) whether actual inheritance of such an acquired bodily change can be demonstrated. The first suggestion seems improbable because no similar rats have appeared in a large related control stock running along with the experimental stock. Furthermore, the character of the disequilibration has appeared to be regularly dependent upon the direction in which the ancestor's were rotated. With respect to the third problem, namely, a possible demonstration of the inheritance of acquired vestibular changes, a number of biologists have offered the suggestion that long continued rotation may have induced the production of toxins or of other substances which, in turn, operate after the fashion of the lens anti-bodies, recently described by Guyer and Smith.

It seems desirable, then, to institute a new series of rotations with a new stock and to use, as well, other means of inducing disturbances in the semicircular canals so that more reliable evidence for or against the apparent cases of inheritance in our own stock may be discovered. It is also desirable to know what morphological and structural changes have taken place in the vestibular areas subsequent to long-continued 
excitation. Fortunately, Professor J. A. Detlefsen, who has cooperated with the writer ever since the first cases of disequilibration appeared, is able to devote a sabbatical year at the Wistar Institute to the further investigation of the facts above described.

\section{R. GRIfHith}

Department of Psychologx,

UNIVERSITY OF TLIIINOIS

\section{THE USEFULNESS OF ANALYTIC ABSTRACTS}

The various ways in which preliminary abstracts should be of service to scientific readers were pointed out about a year ago ${ }^{1}$, but whether such abstracts as actually prepared and published would be worth while could be determined only by experiment. This has been done. After analytic abstracts had been appearing in the Astrophysical Journal and the Physical Review ${ }^{2}$ for over two years the following return post-card questionnaire was sent by the chairman of the Division of Physical Sciences of the National Research Council to each reader, with the request that he underscore in each parenthesis the word or words which represent his answer to the question implied:

I. look through (the Astrophysical Journal, the Physical Review) regularly. Before reading the articles, I read the abstracts (always, usually, sometimes, seldom, never). Instead of reading the articles, I read the abstracts in (many, some, few, no) eases. The abstracts have helped me understand the articles in (some, few, no) eases. The abstracts have proved useful in locating information in (some, few, no) eases. I read the subtitles in the abstraets first (sometimes, never). I find the subtitles of value as an index of the abstract (sometimes, never). The abstracts in general give (too much, too little, about enough) information. I think they should be continued (yes, no).

I have the following suggestions to make:

1 "Scientific Abstracting" by G. S. Fulcher, SCIENCE 54, 291, September 30, 1921.

2 The preliminary abstracts in the Plysical Review are ealled "Synopses" to distinguish them from the abstracts of papers presented at meetings which are printed in connection with the proceedings of the Saciety.
Replies were received from 805 readers, including 83 readers of the Astrophysical Journal, 502 readers of the Physical Review, and 220 readers of both. Although the answers from the three groups have been tabulated separately, the results are so nearly the same for each that only the results for all readers, that is, the percentages of all readers answering each question in each alternative way, will be given here. Since some replies are incomplete, the sum of the percentages is usually less than 100.

1. How frequently are the abstracts read before the articles?

$\begin{array}{lll}\text { always } & \text { by } & 41.9 \text { per cent. of readers. } \\ \text { usually } & \text { by } & 45.9 \text { per cent. of readers. } \\ \text { sometimes } & \text { by } & 9.9 \text { per cent. of readers. } \\ \text { seldom } & \text { by } & 2.1 \text { per cent. of readers. } \\ \text { never } & \text { by } & 0.2 \text { per cent. of readers. }\end{array}$

100.0 per cent.

2. How many abstracts are read instead of the articles?

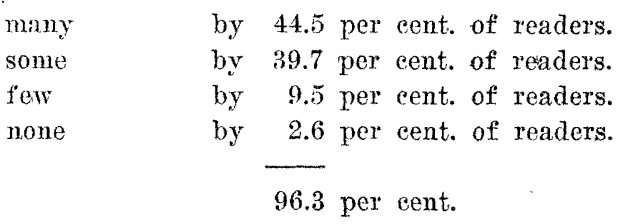

3. How many abstracts helped in understanding the articles?
some helped
few helped
58.1 per cent. of readers.
none helped
17.7 per cènt. of readers.
11.8 per cent. of readers.

87.6 per cent.

4. How many abstracts have proved useful in locating information?

some useful to $\quad 59.3$ per cent. of readers.
few useful to 16.6 per cent. of readers.
none useful to 11.4 per cent. of readers.

none useful to 11.4 per cent. of readers.

87.3 per cent.

5. Should the abstracts be continued? yes $\quad 92.8$ per cent. of readers.

no

4.0 per cent. of readers.

96.8 per cent.

Since the abstracts are read, always or usually, by 88 per cent. of the readers; are read 